\title{
Adsorption Features of Loess Calcareous Nodules to Heavy-Metal Ions in Aqueous Solution
}

Qi Li ${ }^{1,2,3, *}$ and Yanan $\mathrm{Li}^{1,2,3}$

1 Shaanxi Provincial Land Engineering Construction Group Co., Ltd., Shaanxi Key Laboratory of Land Consolidation, Xi'an 710075, China; 2015127001@chd.edu.cn

2 Shaanxi Provincial Land Engineering Construction Group Co., Ltd., Institute of Land Engineering and Technology, Xi'an 710075, China

3 Shaanxi Provincial Land Consolidation Engineering Technology Research Center, Xi'an 710075, China

* Correspondence: 2015126049@chd.edu.cn

Citation: Li, Q.; Li, Y. Adsorption Features of Loess Calcareous Nodules to Heavy-Metal Ions in Aqueous Solution. Coatings 2021, 11, 1314. https://doi.org/10.3390/ coatings11111314

Academic Editor: Artur P. Terzyk

Received: 16 September 2021

Accepted: 27 October 2021

Published: 28 October 2021

Publisher's Note: MDPI stays neutral with regard to jurisdictional claims in published maps and institutional affiliations.

Copyright: (c) 2021 by the authors. Licensee MDPI, Basel, Switzerland. This article is an open access article distributed under the terms and conditions of the Creative Commons Attribution (CC BY) license (https:/ / creativecommons.org/licenses/by/ $4.0 /)$.

\begin{abstract}
This paper explores the use of calcareous tuberculosis as an adsorbent and heavy-metal ions $\left(\mathrm{Cu}^{2+}, \mathrm{Zn}^{2+}, \mathrm{Cd}^{2+}\right.$, and $\left.\mathrm{Pb}^{2+}\right)$ as adsorbates, and the influence of varying levels of particle size, adsorption time, $\mathrm{pH}$, adsorbent dosage, and initial concentration of heavy metals is studied through an experiment of single heavy-metal adsorption. In addition, the impact of the temperature and other factors on the adsorption of heavy-metal ions by calcareous nodules is analyzed to identify the optimal conditions for the adsorption of heavy-metal ions by calcareous nodules. As shown by the research findings, the adsorption rates of $\mathrm{Cu}^{2+}, \mathrm{Zn}^{2+}$, and $\mathrm{Pb}^{2+}$ gradually declined with the increase in particle size, with no evident effect on $\mathrm{Cd}^{2+}$. In the meantime, with further increases in factors such as the adsorption time, adsorbent dosage, and temperature, the adsorption rates of $\mathrm{Cu}^{2+}, \mathrm{Zn}^{2+}, \mathrm{Cd}^{2+}$, and $\mathrm{Pb}^{2+}$ experienced gradual increases. The adsorption rates of $\mathrm{Cu}^{2+}, \mathrm{Zn}^{2+}$, and $\mathrm{Cd}^{2+}$ gradually declined with the increase in initial concentration of heavy-metal ions, whereas the adsorption rate of $\mathrm{Pb}^{2+}$ experience increased first and then declined. As the $\mathrm{pH}$ increased, the adsorption rate of $\mathrm{Cd}^{2+}$ experience increased first and then declined at a slow pace. The adsorption rates of $\mathrm{Cu}^{2+}, \mathrm{Zn}^{2+}$, and $\mathrm{Pb}^{2+}$ increased first and then decreased. The adsorption capacity of calcareous nodules toward the four heavy-metal ions was in the order of $\mathrm{Pb}^{2+}>\mathrm{Zn}^{2+}>\mathrm{Cu}^{2+}>\mathrm{Cd}^{2+}$. When the particle size was set to $0.25 \mathrm{~mm}$, the adsorption time was set to $120 \mathrm{~min}$, and the dosage was set to $0.6 \mathrm{~g}$, the calcareous nodules included $\mathrm{Pb}^{2+}, \mathrm{Zn}^{2+}$, and $\mathrm{Cu}^{2+}$. Moreover, $\mathrm{Cd}^{2+}$ was able to achieve stronger adsorption capacity, with the adsorption rate able to reach $83.33 \%, 77.78 \%, 73.81 \%$, and $81.93 \%$ of its maximum level. Therefore, as the particle size of the heavy-metal ions decreased, the adsorption capacity generally became stronger. As the adsorption time increased, the temperature and the amount of adsorbent also increased. The optimal $\mathrm{pH}$ value for the adsorption of calcareous nodules toward $\mathrm{Pb}^{2+}, \mathrm{Zn}^{2+}, \mathrm{Cu}^{2+}$, and $\mathrm{Cd}^{2+}$ was found to be $7,6,5$, and 8, respectively, and the optimal temperature was $50{ }^{\circ} \mathrm{C}$. In summary, calcareous nodules are a natural, low-cost, and effective adsorbent.
\end{abstract}

Keywords: loess calcareous nodules; heavy-metal ions; single adsorption; adsorption rate

\section{Introduction}

Over recent years, with the rapid progress made in industrialization and urbanization, a large amount of wastewater containing heavy-metal ions such as $\mathrm{Cu}^{2+}, \mathrm{Zn}^{2+}, \mathrm{Cd}^{2+}$, and $\mathrm{Pb}^{2+}$ has been discharged into water ecosystems. As a result, the contamination of water bodies caused by heavy metals has become increasingly severe [1]. Heavy metals feature strong toxicity and can easily migrate but are hardly degraded. Subsequent to entrance into the water body, they can impose severe damage to human health. Therefore, identifying ways of purifying water and removing metal ions has become a research hotspot within the topic of environmental pollution [2]. Given that the treatment of water and metal pollution is deemed a long-term and arduous task, the cost and environmental friendliness must be taken into full account during selection of the treatment methodology. The adsorption 
method is more applicable to various water bodies with a low concentration of heavymetal pollution, mainly due to the advantages of this method, such as fast treatment rate, simple operation, and optimal environmental coordination [3,4]. During the application of adsorption methods, the commonly used adsorbents include activated carbon, chitosan, resin, zeolite, and sepiolite, in addition to clay minerals such as kaolinite, vermiculite, and montmorillonite [5]. According to the research findings, vermiculite features a strong adsorption capacity for $\mathrm{Pb}^{2+}, \mathrm{Cd}^{2+}$, and $\mathrm{Zn}^{2+}$ in water, and sepiolite features an optimal adsorption effect for $\mathrm{Ni}^{2+}, \mathrm{Cd}^{2+}, \mathrm{Zn}^{2+}$, and $\mathrm{Cu}^{2+}$ in water [6-8]. In addition, illite, kaolinite, and montmorillonite feature an optimal adsorption effect on $\mathrm{Cu}^{2+}, \mathrm{Zn}^{2+}, \mathrm{Cr}^{3+}, \mathrm{Cd}^{2+}$, and $\mathrm{Pb}^{2+}$ in water [9].

Loess calcareous nodules are also referred to as ginger stones. They are aggregates of soils of varying sizes and shapes, which are subject to the action of leaching, sedimentation, alteration, and human activities under the circumstances of alternating wet and dry conditions and freeze-thaw conditions in the soil on the Loess Plateau [10]. Calcareous nodules are widely distributed in the heavily eroded Loess Plateau, and they are mainly composed of primary minerals such as calcite, quartz, and feldspar, in addition to layered silicate minerals such as kaolinite, montmorillonite, and illite. In particular, illite and montmorillonite feature a large specific surface area, high activity, and optimal porosity; thus, they are able to effectively adsorb heavy-metal ions in water [11]. Previous studies mainly focused on the origin, distribution, structure, and mechanical properties of loess calcareous nodules, but few of them investigated the adsorption features of heavy-metal ions on the surface of calcareous nodules [10,12-14]. As natural mineral aggregates, calcareous nodules feature advantages such as a wide range of sources, low cost, prevention of secondary pollution when added to water, and ease of application. In addition, the approach of treating waste with waste not only improves the soil body itself, but also lowers the content of heavymetal ions in the water body. They are, thus, regarded as materials with an optimal effect of environmental coordination. For this reason, this paper elaborates on the adsorption features of loess calcareous nodules toward water and heavy-metal ions, and it is expected to lay a theoretical foundation for the application of this adsorbent in eliminating heavy metals from polluted water.

\section{Materials and Methods}

\subsection{Materials}

The loess calcareous nodules used for the experiments were collected from forest land in Tongchuan City, Shaanxi Province, China ( $34^{\circ} 99^{\prime} \mathrm{N}$; $108^{\circ} 92^{\prime}$ E). Calcium nodules of similar size and shape were mainly collected in the surface soil at 0-20 cm depth and air-dried for later use. $\mathrm{Cu}\left(\mathrm{NO}_{3}\right)_{2}, \mathrm{Zn}\left(\mathrm{NO}_{3}\right)_{2}, \mathrm{Cd}\left(\mathrm{NO}_{3}\right)_{2}, \mathrm{~Pb}\left(\mathrm{NO}_{3}\right)_{2}, \mathrm{HNO}_{3}$, and $\mathrm{NaOH}$ were all analytical reagent-grade. The water adopted in the experiments was distilled water, which was used to prepare standard solutions of metal ions.

\subsection{Methods}

2.2.1. Scanning Electron Microscopy and Microwave Digestion of Calcareous Tuberculosis

The calcareous tuberculosis powder was prepared into a suspension, which was then evenly coated on a copper table with a pipette. Subsequent to natural air-drying, the powder was scanned using a high-resolution scanning electron microscope (SU8010, Hitachi, Tokyo, Japan). The chemical composition of calcareous nodules was extracted through the method of microwave digestion using aqua regia-hydrofluoric acid as the reagent, and the extract was measured by an inductively coupled plasma mass spectrometer (ICP-MS, Agilent Technologies Inc., Tokyo, Japan) [15,16].

\subsubsection{Adsorption Kinetics}

Calcareous nodules $(0.4 \mathrm{~g})$ were added to $100 \mathrm{~mL}$ of a $30 \mathrm{mg} / \mathrm{L}$ solution containing $\mathrm{Cu}^{2+}, \mathrm{Zn}^{2+}, \mathrm{Cd}^{2+}$, and $\mathrm{Pb}^{2+}$. Continuous stirring was carried out at $25^{\circ} \mathrm{C}$. Samples of $0.5 \mathrm{~mL}$ were subjected to $1,3,5,15,30,60,90$, and 120 min of shaking, and the contents of 
heavy-metal ions $\left(\mathrm{Cu}^{2+}, \mathrm{Zn}^{2+}, \mathrm{Cd}^{2+}\right.$, and $\left.\mathrm{Pb}^{2+}\right)$ were determined in the supernatant. Each group of experiments was conducted in triplicate.

\subsubsection{Calcium Nodule Adsorption to Heavy-Metal Ions}

Calcareous nodules were used as adsorbents. Aqueous solutions containing heavymetal ions, including $\mathrm{Cu}^{2+}, \mathrm{Zn}^{2+}, \mathrm{Cd}^{2+}$, and $\mathrm{Pb}^{2+}$, were adopted as the objects of adsorption. The experiment on single heavy-metal adsorption was carried out under varying conditions.

The experiment on the size of particles involved taking $0.2 \mathrm{~g}$ of calcium nodules sieved through $1,0.5,0.25,0.18$, and $0.149 \mathrm{~mm}$ meshes, respectively. Subsequently, $50 \mathrm{~mL}$ of $\mathrm{Cu}^{2+}$, $\mathrm{Zn}^{2+}, \mathrm{Cd}^{2+}$, or $\mathrm{Pb}^{2+}$ was added at a concentration of $30 \mathrm{mg} / \mathrm{L}$ and shaken at a constant temperature $\left(25 \pm 1{ }^{\circ} \mathrm{C}\right)$ for $120 \mathrm{~min}$, whereas the supernatant was centrifuged, using ICP-MS to identify the content of heavy-metal ions.

The experiment on the time of adsorption involved taking $0.2 \mathrm{~g}$ of calcic nodules sieved through a $0.25 \mathrm{~mm}$ mesh and $50 \mathrm{~mL}$ of $\mathrm{Cu}^{2+}, \mathrm{Zn}^{2+}, \mathrm{Cd}^{2+}, \mathrm{or} \mathrm{Pb}^{2+}$ added at a concentration of $30 \mathrm{mg} / \mathrm{L}$. Samples were taken at shaking times of 1, 3, 5, 15, 30, 60, 90, and $120 \mathrm{~min}$, and then the content of heavy-metal ions in the supernatant was measured accordingly.

The experiment on the $\mathrm{pH}$ value involved taking $0.2 \mathrm{~g}$ of calcareous nodules sieved through a $0.25 \mathrm{~mm}$ mesh, which were then added to $50 \mathrm{~mL}$ of solutions at a concentration of $30 \mathrm{mg} / \mathrm{L}$ of $\mathrm{Cu}^{2+}, \mathrm{Zn}^{2+}, \mathrm{Cd}^{2+}$, or $\mathrm{Pb}^{2+}$, with the $\mathrm{pH}$ values reaching 4, 5, 6, 7, and 8 . Other experimental conditions were the same as for the experiment on the size of particles.

The experiment on the sorbent dosage involved taking $0.2,0.4,0.6,0.8$, and $1 \mathrm{~g}$ of calcareous nodules sieved through a $0.25 \mathrm{~mm}$ mesh, which were added to $50 \mathrm{~mL}$ solutions containing $30 \mathrm{mg} / \mathrm{L} \mathrm{Cu}^{2+}, \mathrm{Zn}^{2+}, \mathrm{Cd}^{2+}$, or $\mathrm{Pb}^{2+}$. Other experimental conditions were the same as above.

The experiment on the initial concentration of heavy metals involved taking $0.2 \mathrm{~g}$ of calcareous nodules sieved through a $0.25 \mathrm{~mm}$ mesh, which were added to $50 \mathrm{~mL}$ solutions of $\mathrm{Cu}^{2+}, \mathrm{Zn}^{2+}, \mathrm{Cd}^{2+}$, or $\mathrm{Pb}^{2+}$ at concentrations of $10,20,30,50$, or $100 \mathrm{mg} / \mathrm{L}$. Other experimental conditions were the same as above.

The experiment on the adsorption temperature involved taking $0.2 \mathrm{~g}$ of calcareous nodules sieved through a $0.25 \mathrm{~mm}$ mesh, which were added to $50 \mathrm{~mL}$ solutions of $\mathrm{Cu}^{2+}$, $\mathrm{Zn}^{2+}, \mathrm{Cd}^{2+}$, and $\mathrm{Pb}^{2+}$ at a concentration of $30 \mathrm{mg} / \mathrm{L}$. After shaking for $120 \mathrm{~min}$ at temperatures of $20^{\circ} \mathrm{C}, 30^{\circ} \mathrm{C}, 40{ }^{\circ} \mathrm{C}, 50^{\circ} \mathrm{C}$, and $60^{\circ} \mathrm{C}$, the supernatant was centrifuged to identify the content of heavy-metal ions.

The experiment on the adsorption isotherm involved adding the calcareous nodules $(0.2 \mathrm{~g})$ to $50 \mathrm{~mL}$ solutions of $\mathrm{Cu}^{2+}, \mathrm{Zn}^{2+}, \mathrm{Cd}^{2+}$, or $\mathrm{Pb}^{2+}$ at concentrations of $10,20,30,50$, or $100 \mathrm{mg} / \mathrm{L}$, respectively. After shaking at $25^{\circ} \mathrm{C}$ for $5 \mathrm{~h}$, the content of $\mathrm{Cu}^{2+}, \mathrm{Zn}^{2+}, \mathrm{Cd}^{2+}$, or $\mathrm{Pb}^{2+}$ in the supernatant was measured. Each group of experiments was conducted in triplicate.

\subsection{Data Processing}

The adsorption rate was adopted to assess the adsorption capacity of calcium nodules to heavy metals, calculated as follows:

$$
\mathrm{Q}=\left(\mathrm{C}_{\mathrm{i}}-\mathrm{C}_{\mathrm{e}}\right) / \mathrm{C}_{\mathrm{i}} \times 100 \%
$$

where $\mathrm{Q}(\%)$ is the adsorption rate, $\mathrm{C}_{\mathrm{i}}(\mathrm{mg} / \mathrm{kg})$ is the initial concentration of heavy metal, and $\mathrm{C}_{\mathrm{e}}(\mathrm{mg} / \mathrm{kg})$ is the equilibrium concentration of heavy metal added to calcareous nodules.

SPSS 18.0 software was adopted for statistical analysis, and Origin 8.0 software was adopted for plotting.

\section{Results and Analysis}

\subsection{Adsorption Isotherm Experiment}

The fitting parameters of isothermal adsorption are specified in Table 1 . The fitting results of the Langmuir model (Equation (2)) and the Freundlich model bas (Equation (3)) are illustrated in Figure 1. It can be seen from Table 1 that the adsorption of calcareous 
nodules to $\mathrm{Cu}^{2+}, \mathrm{Zn}^{2+}, \mathrm{Cd}^{2+}$, and $\mathrm{Pb}^{2+}$ conformed to the Langmuir model overall, whereas the fitting result of the Freundlich model was better for $\mathrm{Zn}^{2+}$. As can be seen from the Langmuir isotherm model, during the adsorption of $\mathrm{Cu}^{2+}, \mathrm{Cd}^{2+}$, and $\mathrm{Pb}^{2+}$ to calcium nodules, monolayer adsorption and heterogeneous surface adsorption were found to coexist, but monolayer adsorption played the dominant role. Moreover, in the Freundlich isotherm model, nonuniform surface adsorption played the dominant role in the adsorption of $\mathrm{Zn}^{2+}$ to calcareous nodules, mainly composed of silica. The results of our isotherm adsorption experiment on calcareous nodules are consistent with those of other adsorbents whose main component is silica. For example, the research results of Lee et al. in a study of adsorption of $\mathrm{Pb}(\mathrm{II})$ and $\mathrm{Cu}(\mathrm{II})$ metal ions to functionalized large-pore mesoporous silica revealed that the correlation coefficient of the Langmuir isotherm $\left(R^{2}=0.983-0.999\right)$ was higher than that of the Freundlich isotherm $\left(R^{2}=0.826-0.983\right)$ for adsorption to copper ions [17]. Similarly, the research results of Melnyk et al. are consistent with ours, whereby a better fit was obtained with the Langmuir isotherm [18].

$$
\begin{gathered}
\text { Langmuir: } \mathrm{C} / \mathrm{Q}=1 / \mathrm{Kq}_{\mathrm{m}}+\mathrm{C} / \mathrm{q}_{\mathrm{m}} \\
\text { Freundlich: } \lg \mathrm{Q}=\lg \mathrm{KF}+\mathrm{nlg} \mathrm{C}
\end{gathered}
$$

Table 1. Fitness of isotherm models and corresponding parameters.

\begin{tabular}{ccccccc}
\hline & \multicolumn{3}{c}{ Langmuir Model } & \multicolumn{3}{c}{ Freundlich Model } \\
\cline { 2 - 7 } Heavy Metal & $\mathbf{K}(\mathbf{L} / \mathbf{m g})$ & $\mathbf{Q}_{\mathbf{m}}\left(\mathbf{m g} \cdot \mathbf{g}^{-1}\right)$ & $\boldsymbol{R}^{\mathbf{2}}$ & $\begin{array}{c}\mathbf{K}_{\mathbf{F}} \\
(\mathbf{m g} / \mathbf{g}) /(\mathbf{m g} / \mathbf{L})^{\mathbf{1 / n}}\end{array}$ & $\boldsymbol{n}$ & $\boldsymbol{R}^{\mathbf{2}}$ \\
\hline $\mathrm{Cu}^{2+}$ & -2.1111111 & 52.6315789 & 0.9908 & 78.072844 & -0.1023 & 0.677 \\
$\mathrm{Zn}^{2+}$ & 0.53947368 & 121.95122 & 0.988 & 45.593192 & 0.378 & 0.9906 \\
$\mathrm{Cd}^{2+}$ & -1.7845304 & 30.9597523 & 0.9924 & 55.309534 & -0.2322 & 0.9921 \\
$\mathrm{~Pb}^{2+}$ & -1.5471014 & 23.4192037 & 0.9867 & 76.155277 & -0.4468 & 0.5419 \\
\hline
\end{tabular}

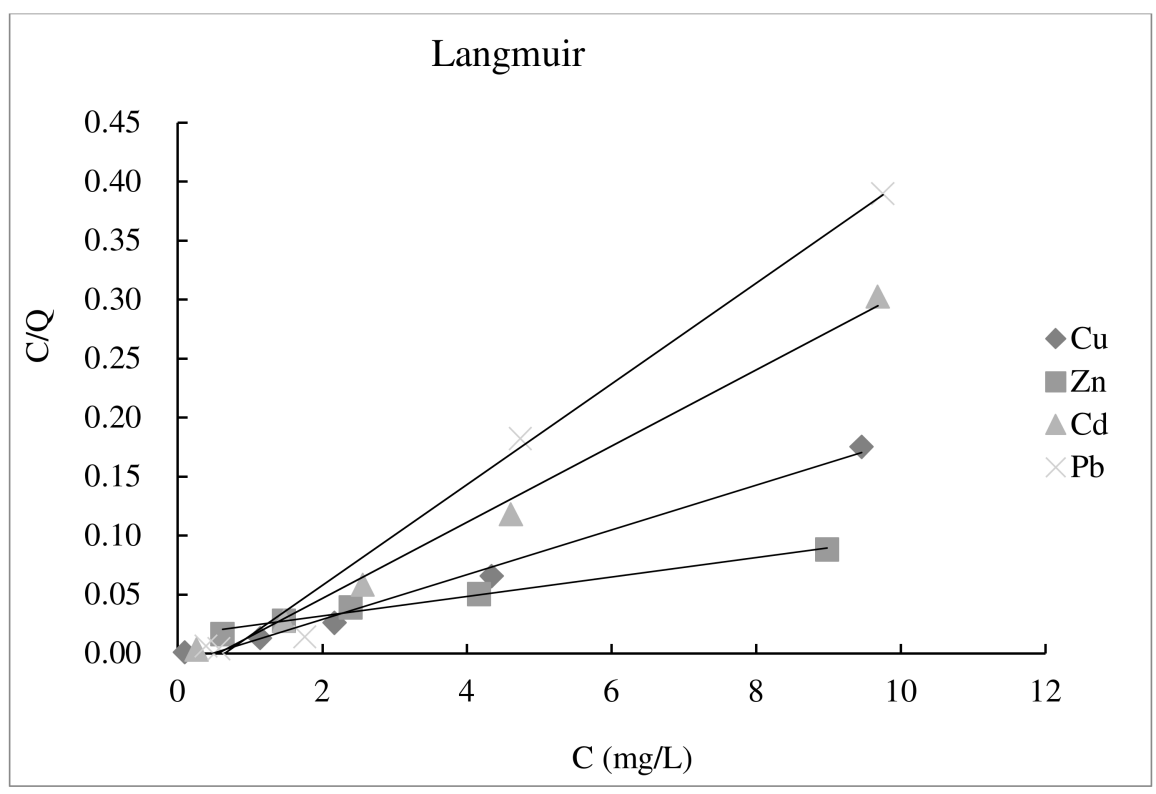

Figure 1. Fitting curves of the Langmuir adsorption isotherm model.

\subsection{Adsorption Kinetics Experiment}

The fitting parameters of the adsorption kinetics are specified in Table 2. The fitting results of the quasi-first-order kinetic model (Equation (4)), the quasi-second-order kinetic model (Equation (5)), and the Elovich kinetic model (Equation (6)) are illustrated in Figure 2. As can be seen from Table 2, the correlation coefficients of the Elovich kinetic model 
describing the adsorption of the calcareous nodules to $\mathrm{Cu}^{2+}, \mathrm{Zn}^{2+}, \mathrm{Cd}^{2+}$, and $\mathrm{Pb}^{2+}$ exceeded those of the quasi-first-order kinetic model and the quasi-second-order kinetic model. The research findings indicate that the adsorption behavior of calcium nodules to $\mathrm{Cu}^{2+}$, $\mathrm{Zn}^{2+}, \mathrm{Cd}^{2+}$, and $\mathrm{Pb}^{2+}$ was more consistent with the Elovich kinetic model. The reason is that the calcareous nodules are mainly formed by evaporation or leaching in nodular authigenic sediments, which are composed of calcium carbonate in semiarid plains or lowland soils. The Elovich kinetic model is quite applicable to processes with large changes in activation energy during the reaction, such as the processes taking place at the interface of soil and sediment.

Elovich kinetic model: $\mathrm{Q}_{\mathrm{t}}=\mathrm{a}+\mathrm{blnt}$

First-order kinetic model: $\ln \left(\mathrm{C}_{0} / \mathrm{C}_{\mathrm{t}}\right)=\mathrm{K}_{1} \mathrm{t}$

Second-order kinetic model: $1 / C_{t}-1 / C_{0}=K_{2} t$

Table 2. Kinetic fitting results.

\begin{tabular}{|c|c|c|c|c|c|c|c|}
\hline \multirow{2}{*}{$\begin{array}{l}\text { Heavy } \\
\text { Metal }\end{array}$} & \multicolumn{3}{|c|}{ Elovich } & \multicolumn{2}{|c|}{ First-Order Dynamics } & \multicolumn{2}{|c|}{ Second-Order Kinetics } \\
\hline & A & $\mathbf{b}$ & $R^{2}$ & $K_{1}\left(\min ^{-1}\right)$ & $R^{2}$ & $\mathrm{~K}_{2}\left(10^{-5} \mathrm{~g} \cdot \mathrm{mg}^{-1} \cdot \mathrm{min}^{-1}\right)$ & $R^{2}$ \\
\hline $\mathrm{Cu}^{2+}$ & 17.817 & 12.634 & 0.938 & 0.0017 & 0.6995 & 0.0007 & 0.7299 \\
\hline $\mathrm{Zn}^{2+}$ & 65.842 & 4.9672 & 0.9042 & 0.0007 & 0.6062 & 0.0003 & 0.6242 \\
\hline $\mathrm{Cd}^{2+}$ & 6.7267 & 8.1169 & 0.9817 & 0.001 & 0.7941 & 0.0004 & 0.8068 \\
\hline $\mathrm{Pb}^{2+}$ & 8.1764 & 23.856 & 0.8958 & 0.0039 & 0.8061 & 0.0018 & 0.8268 \\
\hline
\end{tabular}

Elovich kinetic model

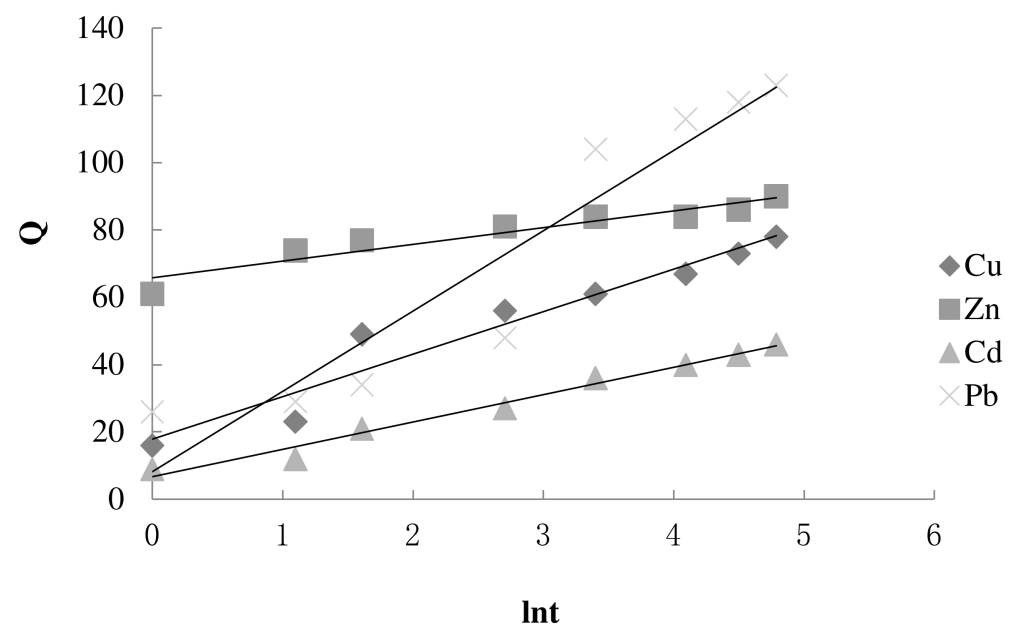

Figure 2. Cont. 
First-order kinetic model

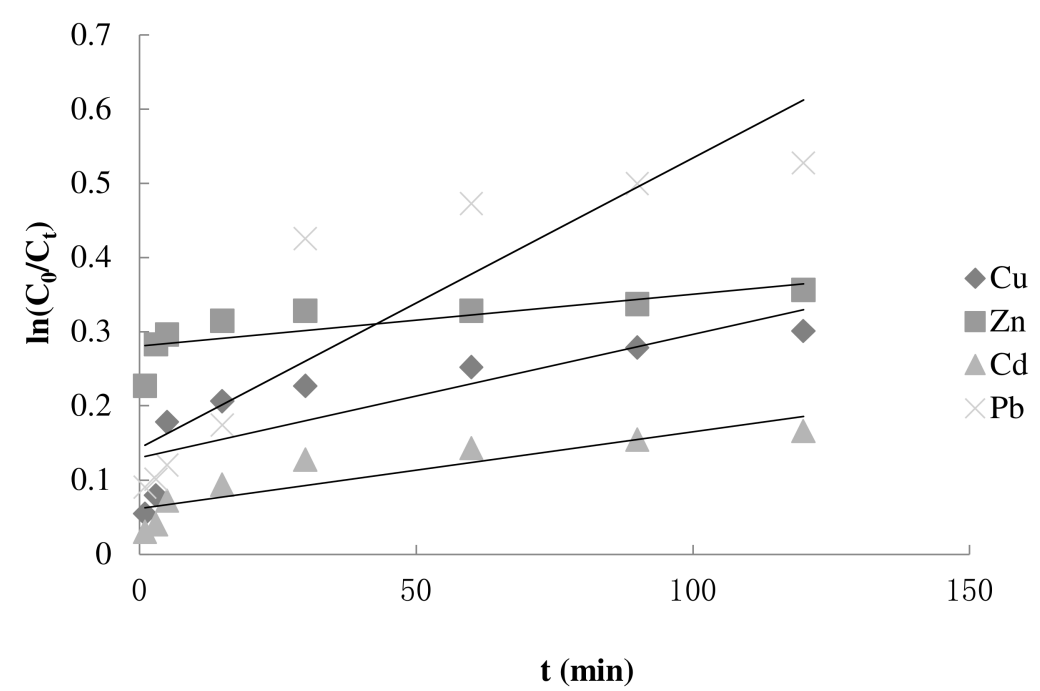

Second-order kinetic model

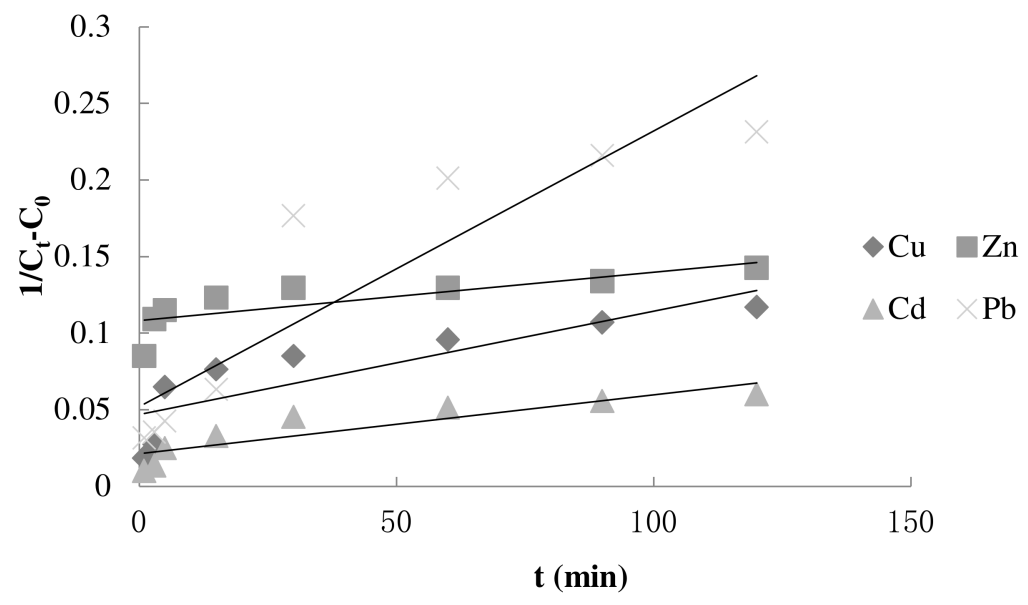

Figure 2. Fitting curves of the adsorption kinetics models.

\subsection{Micromorphology and Chemical Composition of Calcareous Nodules}

As can be seen from the scanning electron micrograph (illustrated in Figure 3), the calcareous nodules featured a compact texture, a rough surface, and a stepped shape, whereas the particles were smooth and had no evident rhomboids. Some of the particles were found to have large pores. The particles were of varying sizes and shapes, and they primarily existed in the form of rods, ellipses, flakes, thin strips, etc. The thin strips and rods are likely to be illite, the ellipses are likely to be iron oxide, and the flakes are likely to be kaolinite and montmorillonite [19]. The adsorption of calcium nodules to heavymetal ions in water is linked to the type and content of minerals. With respect to the chemical composition, the major component of calcareous nodules was $\mathrm{SiO}_{2}$, followed by $\mathrm{CaO}$ and $\mathrm{Al}_{2} \mathrm{O}_{3}$. The sum of the three components was roughly $90 \%$. In contrast, $\mathrm{K}_{2} \mathrm{O}, \mathrm{NaO}, \mathrm{MgO}$, and $\mathrm{Fe}_{2} \mathrm{O}_{3}$ are easily leached out with water, and their content was relatively low (as specified in Table 3). The ratio of silicon to aluminum in calcareous nodules $\left(\mathrm{SiO}_{2} / \mathrm{Al}_{2} \mathrm{O}_{3}\right)$ was found to be 2.89. Combined with the percentage of each oxide, it can be inferred that the calcareous nodules mainly included 2:1 collision type minerals such as illite and montmorillonite. The 2:1 collision type minerals feature a large specific surface area and fine particle size, with an optimal effect toward the adsorption and precipitation of heavy-metal ions. Therefore, calcium nodules can be adopted to adsorb and eliminate heavy-metal ions in water $[20,21]$. 

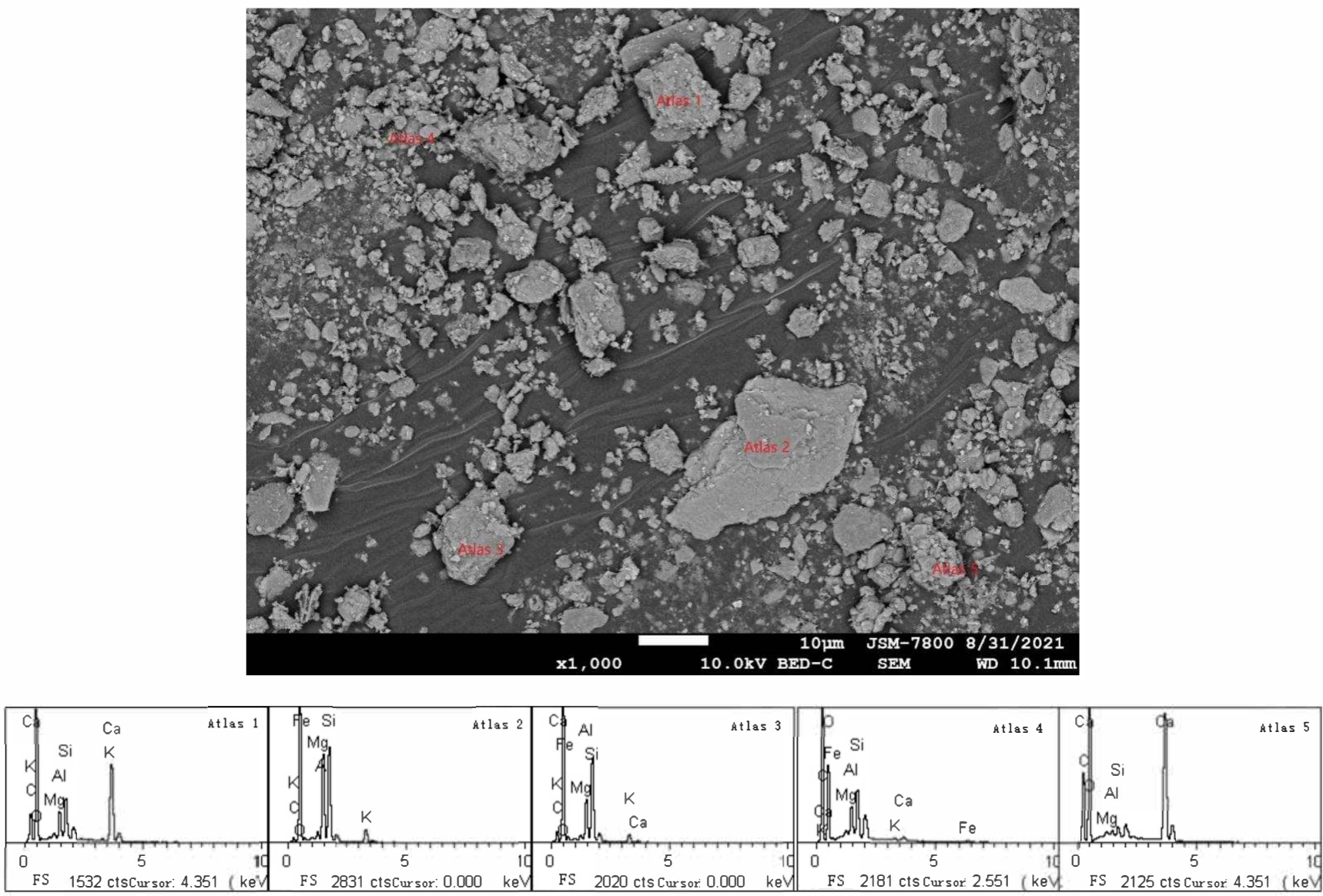

Figure 3. Scanning electron micrograph of calcareous nodules. 1. Silicate (calcium-based); 2 . Silicate + a small amount of iron oxide; 3 . Silicate + a small amount of iron oxide; 4 . Silicate + a small amount of iron oxide; 5 . Calcium oxide + a small amount of silicate.

Table 3. Chemical composition of calcareous modules.

\begin{tabular}{ccccccccc}
\hline Chemical Components & $\mathrm{K}_{2} \mathrm{O}$ & $\mathrm{CaO}$ & $\mathrm{NaO}$ & $\mathrm{MgO}$ & $\mathrm{Al}_{2} \mathrm{O}_{3}$ & $\mathrm{Fe}_{2} \mathrm{O}_{3}$ & $\mathrm{SiO}_{2}$ & $\mathrm{SiO}_{2} / \mathrm{Al}_{2} \mathrm{O}_{3}$ \\
\hline Content (\%) & 2.16 & 34.57 & 1.23 & 1.78 & 14.36 & 4.34 & 41.56 & 2.89 \\
\hline
\end{tabular}

\subsection{Impact of the Particle Size on the Adsorption of Heavy-Metal Ions by Calcium Nodules}

The adsorption rate of heavy-metal ions was subject to significant changes in accordance with the size of the calcium nodules (as illustrated in Figure 4). When the particle size ranged between $0.149 \mathrm{~mm}$ and $0.25 \mathrm{~mm}$, the adsorption rate of $\mathrm{Cu}^{2+}, \mathrm{Zn}^{2+}$, and $\mathrm{Pb}^{2+}$ declined at a slow pace. For particle sizes smaller than $0.25 \mathrm{~mm}$, the adsorption rate declined to a significant extent. The adsorption rates of $\mathrm{Cu}^{2+}, \mathrm{Zn}^{2+}$, and $\mathrm{Pb}^{2+}$ ranged from $20.33 \%$ to $85.00 \%, 28.67 \%$ to $89.33 \%$, and $43.67 \%$ to $82.00 \%$, respectively. When the particle size of $\mathrm{Cd}^{2+}$ ranged between $0.149 \mathrm{~mm}$ and $0.25 \mathrm{~mm}$, the adsorption rate declined to a relatively significant extent (by $14.67 \%$ ). For particle sizes exceeding $0.25 \mathrm{~mm}$, the adsorption rate was generally stable. As the particle size of calcium nodules further expanded, the adsorption rate of heavy-metal ions gradually declined. The reason behind is perhaps that, as the particle size of the calcareous nodules of the same mass increased, parameters such as the specific surface area and the relative content of layered silicate minerals decreased, including montmorillonite and illite, thereby lowering the adsorption rate of heavy-metal ions. Furthermore, the discrepancy in the content of carbonate, sulfate, and hydrated oxides of iron, aluminum, and magnesium in calcium nodules with varying particle sizes would also have an impact on the adsorption effect of heavy-metal ions. It was observed 
that, as the particle size decreased, the solution likely became more turbid, with a longer time required before settling. Therefore, it was better to opt for calcareous nodules sieved through $0.25 \mathrm{~mm}$ mesh when conducting the adsorption of heavy-metal ions.

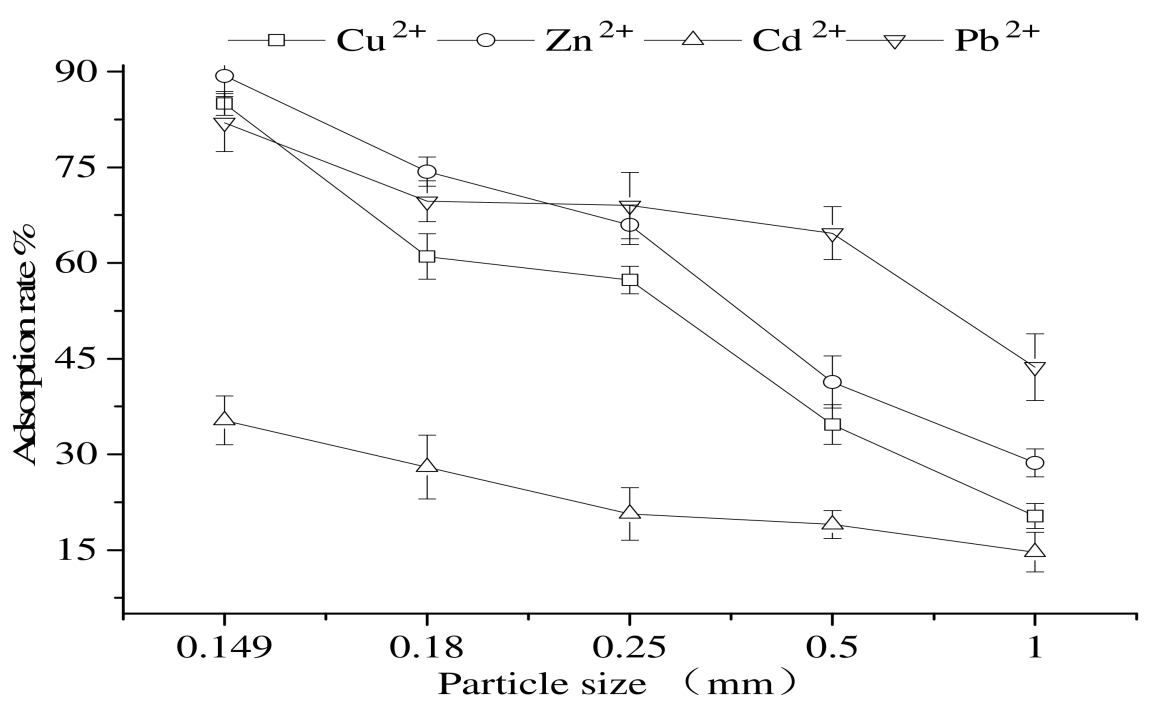

Figure 4. Effects imposed by calcium nodules of varying particle size on the adsorption of $\mathrm{Cu}^{2+}$, $\mathrm{Zn}^{2+}, \mathrm{Cd}^{2+}$, and $\mathrm{Pb}^{2+}$ in solution $\left(25^{\circ} \mathrm{C}, \mathrm{pH} 7\right)$.

\subsection{Impact of the Adsorption Time on the Adsorption of Heavy-Metal Ions by Calcium Nodules}

With an increase in experimental time, the adsorption rate of heavy-metal ions gradually increased, but the adsorption curve showed a different trend (as illustrated in Figure 5). The adsorption rates of $\mathrm{Cd}^{2+}$ and $\mathrm{Pb}^{2+}$ experienced significant increases within the adsorption time of 1 to $60 \mathrm{~min}$, whereas the increase in adsorption rates slowed with a further increase in adsorption time. Compared with $\mathrm{Cd}^{2+}$ and $\mathrm{Pb}^{2+}, \mathrm{Cu}^{2+}$ and $\mathrm{Zn}^{2+}$ were able to attain a higher adsorption rate in a shorter time (within $15 \mathrm{~min}$ ). $\mathrm{Cu}^{2+}, \mathrm{Zn}^{2+}, \mathrm{Cd}^{2+}$, and $\mathrm{Pb}^{2+}$ were able to attain the high adsorption rates within $30 \mathrm{~min}$, eventually reaching maximum rates of $26 \%, 30.00 \%, 15.33 \%$, and $41.00 \%$, respectively. $\mathrm{Cu}^{2+}, \mathrm{Zn}^{2+}, \mathrm{Cd}^{2+}$, and $\mathrm{Pb}^{2+}$ exhibited better adsorption effects within $60 \mathrm{~min}$. This was likely caused by the combination of mineral types and their contents in calcareous nodules. Due to the large concentration gradient existing between the calcium nodules and the solutions for heavymetal adsorption, adsorption occurred at a relatively faster pace. The adsorption rate of calcium nodules to the four heavy-metal ions increased smoothly after $60 \mathrm{~min}$. According to the adsorption time, the degree of adsorption of heavy-metal ions can be determined to a certain extent. At adsorption times longer than $60 \mathrm{~min}$, the adsorption rates of the four heavy-metal ions experienced slight increases with time. The research findings indicate that the adsorption time is not the primary contributing factor to the adsorption rate of heavy-metal ions. Accordingly, a time of $120 \mathrm{~min}$ was selected for comparative analysis. 


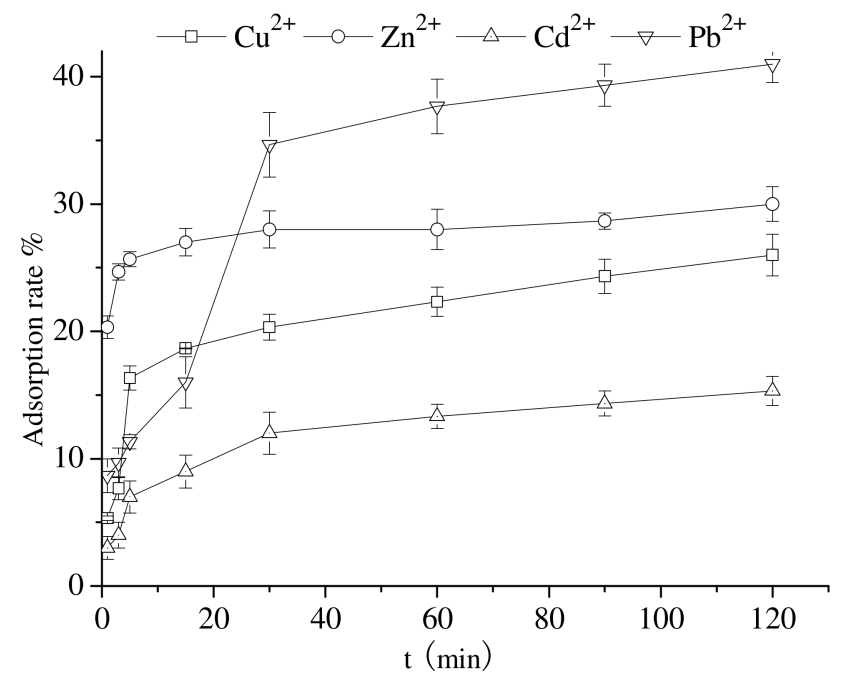

Figure 5. Effects imposed by the adsorption time on the adsorption of $\mathrm{Cu}^{2+}, \mathrm{Zn}^{2+}, \mathrm{Cd}^{2+}$, and $\mathrm{Pb}^{2+}$ in solution $\left(25^{\circ} \mathrm{C}, \mathrm{pH} 7\right)$.

\subsection{Impact of $\mathrm{pH}$ Value on the Adsorption of Heavy-Metal Ions by Calcium Nodules}

The $\mathrm{pH}$ value is a vital factor mediating the adsorption rate, which is linked to the chemical properties of various heavy-metal ions and their existence in solution. As illustrated in Figure 6, when $\mathrm{pH}=4$, the adsorption rates of calcium nodules to $\mathrm{Cu}^{2+}, \mathrm{Zn}^{2+}$, $\mathrm{Cd}^{2+}$, and $\mathrm{Pb}^{2+}$ reached the minimum levels of $16.00 \%, 19.67 \%, 9.67 \%$, and $10.33 \%$, respectively. At this $\mathrm{pH}$, calcium carbonate and the oxides of iron, aluminum, and magnesium in the calcareous nodules were subject to decomposition under the action of $\mathrm{H}^{+}$, thereby damaging their structure and properties. In addition, the concentrations of $\mathrm{Ca}^{2+}, \mathrm{Fe}^{2+}, \mathrm{Al}^{3+}$, and $\mathrm{Mg}^{2+}$ in the solutions constantly increased. As a result, a competitive relationship among $\mathrm{Cu}^{2+}, \mathrm{Zn}^{2+}, \mathrm{Cd}^{2+}$, and $\mathrm{Pb}^{2+}$ in the solutions was formed, thus impacting the adsorption of heavy-metal ions. As the $\mathrm{pH}$ value gradually increased, the adsorption rate of $\mathrm{Cd}^{2+}$ first increased rapidly and then slowly, reaching a maximum of $30.33 \%(\mathrm{pH}=8)$. The adsorption rates of $\mathrm{Zn}^{2+}$ and $\mathrm{Pb}^{2+}$ first increased and then declined, reaching a maximum of $40.67 \%$ $(\mathrm{pH}=6)$ and $49.67 \%(\mathrm{pH}=7)$, respectively. When the $\mathrm{pH}$ value was set to 5 , the adsorption rate of $\mathrm{Cu}^{2+}$ reached its maximum. When the $\mathrm{pH}$ exceeded 5 , the adsorption rate declined to a significant extent, whereas it remained basically stable in the $\mathrm{pH}$ value range of 6 to 8 .

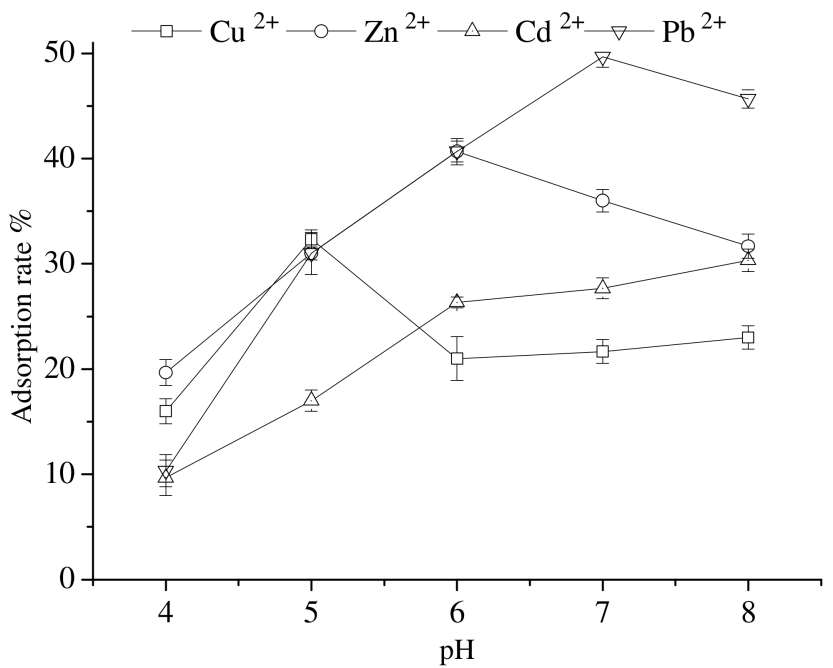

Figure 6. Effects of $\mathrm{pH}$ value on the adsorption of $\mathrm{Cu}^{2+}, \mathrm{Zn}^{2+}, \mathrm{Cd}^{2+}$, and $\mathrm{Pb}^{2+}$ in solution $\left(25^{\circ} \mathrm{C}\right)$. 
As shown by the research findings, the metal ions showed different patterns as a function of $\mathrm{pH} . \mathrm{Cd}^{2+}$ adsorption mainly exhibits characteristics of complicated and potential adsorption [4]. Under such circumstances, a higher $\mathrm{pH}$ value is more conducive to the adsorption of $\mathrm{Cd}^{2+}$. On the other hand, $\mathrm{Cu}^{2+}, \mathrm{Zn}^{2+}$, and $\mathrm{Pb}^{2+}$ are primarily adsorbed through precipitation. As the $\mathrm{pH}$ value increases, they are gradually transformed into hydroxide complex ions. In particular, $\mathrm{Cu}^{2+}$ starts to precipitate as the $\mathrm{pH}$ value exceeds 5 , whereas $\mathrm{Zn}^{2+}$ starts to precipitate as the $\mathrm{pH}$ value exceeds 6 , and $\mathrm{Pb}^{2+}$ starts to precipitate as the $\mathrm{pH}$ value exceeds 7 . Therefore, with an increase in the $\mathrm{pH}$ value, the changes in the adsorption rates of the four heavy-metal ions varied [22-25].

\subsection{Impact of the Amount of Adsorbent on the Adsorption of Heavy-Metal Ions by Calcium Nodules}

The adsorption rates of calcium nodules to $\mathrm{Cu}^{2+}, \mathrm{Zn}^{2+}, \mathrm{Cd}^{2+}$, and $\mathrm{Pb}^{2+}$ in solution gradually increased with the increasing amount of calcium nodules (illustrated in Figure 7). The adsorption rate increased rapidly between dosages of $0.2 \mathrm{~g}$ and $0.6 \mathrm{~g}$, before slowing down. The amount of calcareous nodules weakly impacted the adsorption rate of $\mathrm{Cd}^{2+}$, only increasing from $16.00 \%$ and $27.67 \%$. On the other hand, the amount of calcareous nodules most evidently impacted the adsorption rate of $\mathrm{Pb}^{2+}$, increasing from $43.00 \%$ and $76.00 \%$, a nearly twofold increase. The amount of calcareous nodules increased the adsorption rate according to the following order: $\mathrm{Pb}^{2+}>\mathrm{Zn}^{2+}>\mathrm{Cu}^{2+}>\mathrm{Cd}^{2+}$. Specifically, the maximum adsorption rates of $\mathrm{Cu}^{2+}$ and $\mathrm{Cd}^{2+}$ were lower than $40 \%$, whereas the adsorption rate of $\mathrm{Pb}^{2+}$ reached a level as high as $80 \%$. This is likely linked to the discrepancy in the electronegativity of $\mathrm{Cu}^{2+}, \mathrm{Zn}^{2+}, \mathrm{Cd}^{2+}$, and $\mathrm{Pb}^{2+}[26,27]$. Although a high dosage of calcium nodules was conducive to increasing the adsorption rate of heavy-metal ions, it also led to turbid water and a poor visual effect. Therefore, $0.6 \mathrm{~g}$ was deemed most suitable for practical application.

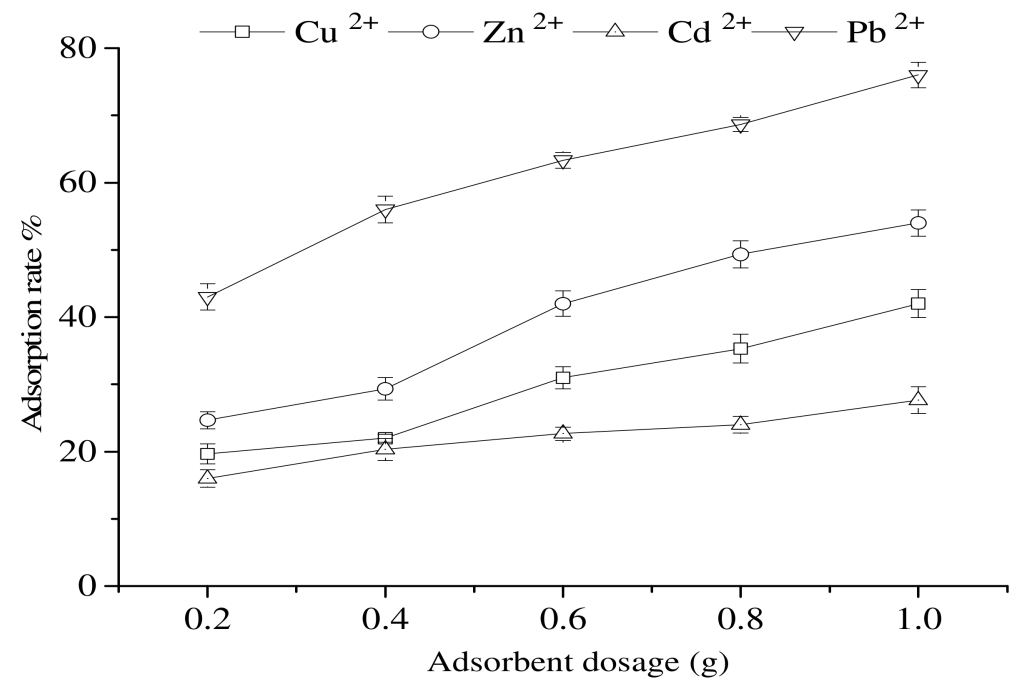

Figure 7. Effects of the amount of adsorbent on the adsorption of $\mathrm{Cu}^{2+}, \mathrm{Zn}^{2+}, \mathrm{Cd}^{2+}$, and $\mathrm{Pb}^{2+}$ in solution $\left(25^{\circ} \mathrm{C}, \mathrm{pH} 7\right)$.

3.8. Impact of the Initial Concentration of Heavy Metals on the Adsorption of Heavy-Metal Ions by Calcium Nodules

As the initial concentration of heavy-metal ions increased, the adsorption rates of calcium nodules to $\mathrm{Cu}^{2+}, \mathrm{Zn}^{2+}$, and $\mathrm{Cd}^{2+}$ showed a significant declining trend, whereas that of $\mathrm{Pb}^{2+}$ first increased and then decreased (as illustrated in Figure 8). This is likely due to the fact that, at a low initial concentration, there are numerous adsorption sites on the surface of calcareous nodules; thus, the adsorption rate decreased with the concentration of heavy-metal ions in solution as the adsorption sites became saturated. The initial 
concentration of heavy-metal ions had a much greater impact on the adsorption rates of $\mathrm{Cu}^{2+}, \mathrm{Cd}^{2+}$, and $\mathrm{Pb}^{2+}$ than $\mathrm{Zn}^{2+}$. At concentrations up to $100 \mathrm{mg} / \mathrm{L}$, the adsorption rate of $\mathrm{Zn}^{2+}$ changed most slowly, declining by merely $27.80 \%$. On the other hand, the adsorption rates of $\mathrm{Cu}^{2+}, \mathrm{Cd}^{2+}$, and $\mathrm{Pb}^{2+}$ declined to a significant extent by $84.60 \%, 70.80 \%$, and $69.00 \%$ respectively. The adsorption rates of the four heavy-metal ions were optimal at lower concentrations. Up to a concentration of $30 \mathrm{mg} / \mathrm{L}$, the adsorption rate of $\mathrm{Pb}^{2+}$ remained above $40 \%$, despite its declining trend. A similar observation was made for $\mathrm{Cu}^{2+}$ up to a concentration of $20 \mathrm{mg} / \mathrm{L}$. The adsorption rates of $\mathrm{Cd}^{2+}$ and $\mathrm{Zn}^{2+}$ were lower than $30 \%$ up to a concentration of $20 \mathrm{mg} / \mathrm{L}$, reaching the maximum levels of $74.00 \%$ and $38.00 \%$, respectively, at $10 \mathrm{mg} / \mathrm{L}$. Therefore, the calcium nodules can be used for the treatment of low-concentration wastewater.

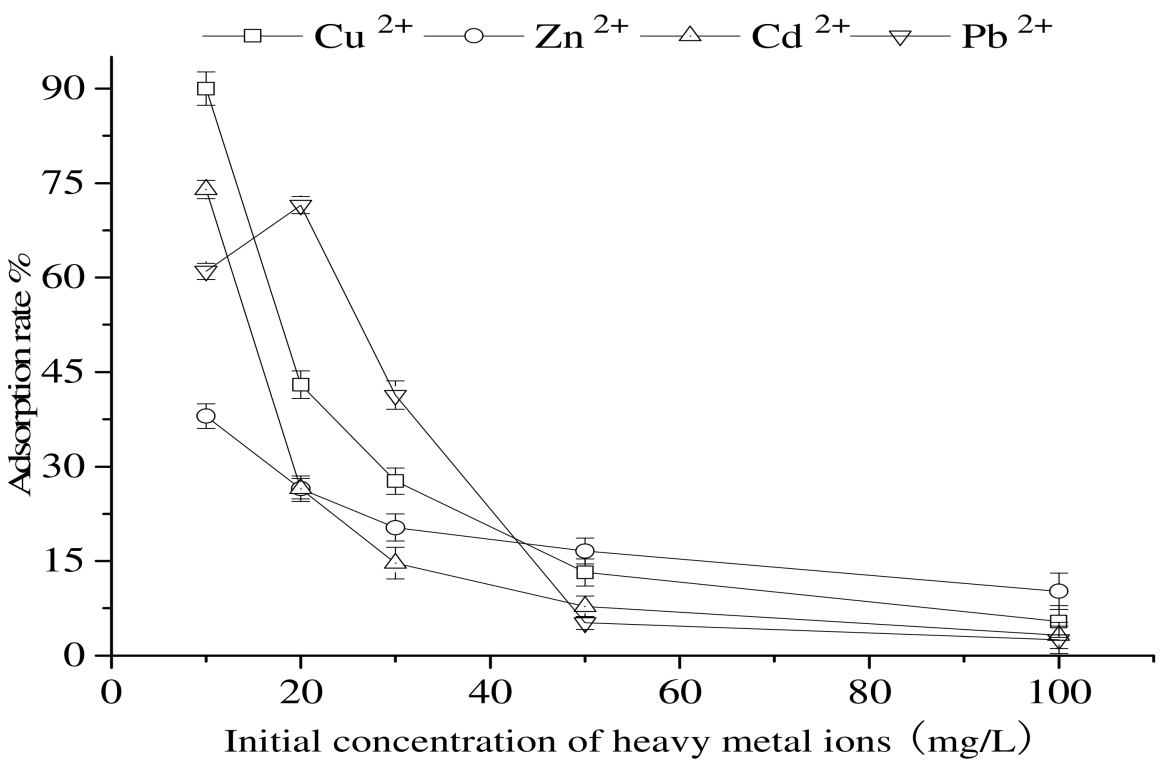

Figure 8. Effects of the initial concentration of heavy-metal ions on the adsorption of $\mathrm{Cu}^{2+}, \mathrm{Zn}^{2+}$, $\mathrm{Cd}^{2+}$, and $\mathrm{Pb}^{2+}$ in solution $\left(25^{\circ} \mathrm{C}, \mathrm{pH} 7\right)$.

\subsection{Impact of the Temperature on the Adsorption of Heavy-Metal Ions by Calcium Nodules}

As the temperature increased, the adsorption rates of calcium nodules to $\mathrm{Cu}^{2+}, \mathrm{Zn}^{2+}$, $\mathrm{Cd}^{2+}$, and $\mathrm{Pb}^{2+}$ all increased (as illustrated in Figure 9), indicating that heat is conducive to the adsorption process. When the temperature ranged between $20{ }^{\circ} \mathrm{C}$ and $40{ }^{\circ} \mathrm{C}$, the adsorption rates experienced a slow increase. When the temperature reached $40{ }^{\circ} \mathrm{C}$, the adsorption rates increased sharply. The contributing factor is likely that, as the temperature increased further, the adsorption and exchange rates of heavy-metal ions also increased. The order of impact of the changing temperature on the adsorption of heavymetal ions to calcium nodules was as follows: $\mathrm{Pb}^{2+}<\mathrm{Cu}^{2+}<\mathrm{Zn}^{2+}<\mathrm{Cd}^{2+}$. Specifically, within the range of $20-40{ }^{\circ} \mathrm{C}$, temperature had a weak effect on the adsorption rate of $\mathrm{Pb}^{2+}$, with the adsorption rate increasing by merely $5.67 \%$. When the temperature increased to $60{ }^{\circ} \mathrm{C}$, the adsorption rate increased by $46.00 \%$. The adsorption rates of $\mathrm{Cu}^{2+}, \mathrm{Zn}^{2+}$ and $\mathrm{Cd}^{2+}$ increased linearly with increasing temperature. When the temperature increased to $60{ }^{\circ} \mathrm{C}$, the adsorption rates increased by $55.67 \%, 66.33 \%$, and $73.67 \%$, respectively. When the temperature was set to $50{ }^{\circ} \mathrm{C}$, the adsorption rates of $\mathrm{Cu}^{2+}, \mathrm{Zn}^{2+}, \mathrm{Cd}^{2+}$, and $\mathrm{Pb}^{2+}$ were found to reach $79.00 \%, 76.00 \%, 72.00 \%$, and $70.00 \%$, respectively, of their maximum adsorption rates. Although an increase in temperature enhanced the adsorption effect of heavy-metal ions, an excessively high temperature risks lowering the survival rate of aerobic microorganisms in the water body, thus imposing a negative impact on the decomposition of other contaminants by the microorganisms in the water body. Accordingly, $50{ }^{\circ} \mathrm{C}$ was selected as the ideal temperature. 


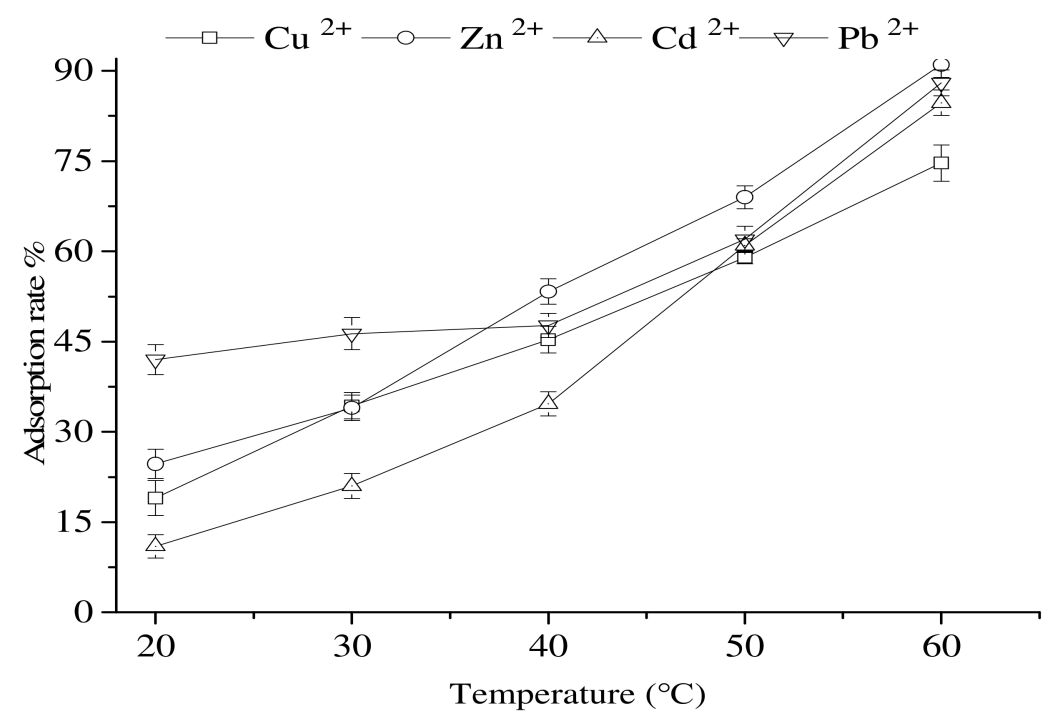

Figure 9. Effects of temperature on the adsorption of $\mathrm{Cu}^{2+}, \mathrm{Zn}^{2+}, \mathrm{Cd}^{2+}$, and $\mathrm{Pb}^{2+}$ in solution.

\section{Discussion}

Since heavy metals exhibit significant toxicity to humans, animals, plants, and microorganisms and are not able to be degraded by microorganisms, wastewater containing heavy metals has become a major environmental concern around the world [28]. Compared with other approaches, the adsorption method features the advantages of simple operation, high efficiency, and low cost; thus, it has been widely adopted in the treatment of heavy-metal wastewater [4]. The adsorbent is the core element during the application of the adsorption method, and its performance impacts both the quality and the efficiency of separation. At present, the adsorbents adopted in the treatment of heavy metals can be divided into natural adsorbents, biological adsorbents, and synthetic adsorbents according to their source and chemical structure [29].

Loess calcium is categorized as a natural adsorbent, but few studies have been carried out on this adsorbent so far. Nevertheless, some scholars have carried out research on the adsorption effect of other adsorbents toward water containing heavy metals. As shown by previous results, the $\mathrm{pH}$ value, time, adsorbent dosage, temperature, and initial concentration of heavy metals are crucial factors affecting the adsorption effects of varying adsorbents, consistent with our research findings [1,2,4-6,29-33]. For instance, Sheikhhosseini et al. elaborated on the competitive sorption of nickel, cadmium, zinc, and copper on palygorskite and sepiolite silicate clay minerals [8]. Their research findings indicated that palygorskite and sepiolite can effectively eliminate $\mathrm{Cu}$ from solution regardless of the presence of other metals. Zou et al. adopted corn stalks to prepare biochar, conducted experiments on the adsorption effects of heavy metals including $\mathrm{Cd}^{2+}$ and $\mathrm{Pb}^{2+}$, and analyzed the capacity and efficiency of the biochar's adsorption to heavy metals [3]. Their experimental results showed that the optimal adsorption condition for $\mathrm{Cd}^{2+}$ was reached when the $\mathrm{pH}$ value was set to 5 , and the adsorption equilibrium amounted to $120 \mathrm{~min}$. The optimal adsorption condition for $\mathrm{Pb}^{2+}$ was reached when the $\mathrm{pH}$ value was set to 1 , and the adsorption equilibrium amounted to $60 \mathrm{~min}$. These findings are basically consistent with the results in this paper. Li et al. studied the adsorption mechanism of corn stover biochar toward Cd(II) [4]. Their experimental results indicated that, with an increase in the $\mathrm{pH}$ value, the adsorption rate constantly increased, which is consistent with our research findings. However, upon reaching a certain threshold, the adsorption rates of various heavy metals increase slowly or even decline. According to Peng's research, the optimal $\mathrm{pH}$ value for the adsorption of various heavy-metal ions may differ due to their discrepancy in metal electronegativity, in addition to the standard reduction potential of heavy-metal ions and the first stability constant of the associated metal hydroxide [29]. Furthermore, 
a proper amount of adsorbent helps achieve an optimal effect. On the other hand, as the adsorption time is lengthened, the adsorption effect is also enhanced, but this effect slows over time; therefore, an optimal time should be selected. Lastly, an increase in temperature leads to an enhanced adsorption effect, but the most suitable temperature varies according to the target heavy metal. The aforementioned research conclusions are overall consistent with our research findings.

\section{Conclusions}

Different adsorption conditions impose varying effects on the adsorption of heavymetal ions by calcium nodules. According to our results, we reached four conclusions, as outlined below.

First, it is better to opt for calcium nodules that pass through a $0.25 \mathrm{~mm}$ sieve when promoting the adsorption of heavy-metal ions.

Second, as the adsorption time and the amount of adsorbent increase, the adsorption rates of $\mathrm{Cu}^{2+}, \mathrm{Zn}^{2+}, \mathrm{Cd}^{2+}$, and $\mathrm{Pb}^{2+}$ increase rapidly before slowing down, with quite similar kinetics. The adsorption time is not a major contributing factor to the adsorption rate of heavy-metal ions. Accordingly, a duration of $120 \mathrm{~min}$ is deemed the best option. Although a high amount of calcium nodules is conducive to increasing the adsorption rates of heavy-metal ions, a high dosage is likely to lead to turbid water and a poor visual effect. Thus, a dosage of $0.6 \mathrm{~g}$ is considered appropriate for practical application.

Third, both the $\mathrm{pH}$ value and the temperature impose a great impact on the adsorption of heavy-metal ions to calcium nodules. However, proper levels should be selected as a function of the heavy metal. In particular, the optimal $\mathrm{pH}$ values for the adsorption of $\mathrm{Pb}^{2+}, \mathrm{Zn}^{2+}, \mathrm{Cu}^{2+}$, and $\mathrm{Cd}^{2+}$ were $7,6,5$, and 8, respectively. The optimal temperature for adsorption was found to be $50{ }^{\circ} \mathrm{C}$.

Fourth, judging by the impact of the initial concentration of heavy metals on their adsorption to calcium nodules, calcium nodules are more applicable for the treatment of low-concentration wastewater.

Generally, as the particle size of heavy-metal ions decreases, the adsorption capacity increases, whereas a longer adsorption time, higher temperature, and greater amount of adsorbent improve the adsorption effect. In summary, calcareous nodules can be used as pure natural adsorbents that are convenient to obtain and low in cost, with a good adsorption effect.

Author Contributions: Q.L. designed and developed the research idea; Y.L. collected and processed data; Q.L. and Y.L. participated in drafting the manuscript; Q.L. contributed to the scientific contentand editing of the article; and all the authors revised the manuscript. All authors have read and agreed to the published version of the manuscript.

Funding: The Fund Project of Shaanxi Key Laboratory of Land Consolidation (Program No.2019-ZD05). Institutional Review Board Statement: Not applicable.

Informed Consent Statement: Not applicable.

Data Availability Statement: The data presented in this study are available on request from the corresponding author. The data are not publicly available due to the data author belongs to the unit of its own experiment.

Acknowledgments: The Research Square Platform LLC is thanked for improving the article.

Conflicts of Interest: The authors declare no conflict of interest.

\section{References}

1. Zhang, Z.; Bao, L.I.; Liang, R. Comparison of sediment heavy metal fractions at estuary and center of Nanyang Zone from Nansi Lake, China. Huanjing Kexue Xuebao/Acta Sci. Circumstantiae 2015, 35, 1408-1416.

2. Wang, Y.Y.; Liu, Y.X.; Lu, H.H.; Yang, R.Q.; Yang, S.M. Competitive adsorption of Pb (II), Cu (II), and Zn (II) ions onto hydroxyapatite-biochar nano composite in aqueous solutions. J. Solid State Chem. 2018, 261, 53-61. [CrossRef] 
3. Zou, J.; Sun, D.; Zhao, J.; Wang, S.; Li, S.; Li, W.; Lv, Y.; Dou, H. Adsorption of heavy metal Cd, Pb by maize straw Biochar. J. Beihua Univ. 2018, 281, 96-99.

4. Li, L.; Lu, Y.; Liu, Y.; Sun, H.W.; Liang, Z.Y. Adsorption mechanisms of cadmium (II) on biochars derived from corn straw. J. Agro-Environ. Sci. 2012, 31, 2277-2283.

5. Liu, J.; Liu, L.; Xue, J. Research progress on treatment of heavy metal wastewater by adsorption. Environ. Chem. 2018, 37, 2016-2024.

6. Hu, H.; Liu, G. The trend of heavy metal wastewater treatment by adsorption method. In Proceedings of the 20122 nd International Conference on Remote Sensing, Environment and Transportation Engineering, Nanjing, China, 1-3 June 2012.

7. Ji, Z.; Wu, X.F.; Li, Y.; Feng, C. Kinetic adsorption and change in chemical potential of heavy metal ions in aqueous solutions. Environ. Chem. 2015, 11, 53-61.

8. Sheikhhosseini, A.; Shirvani, M.; Shariatmadari, H. Competitive sorption of nickel, cadmium, zinc and copper on palygorskite and sepiolite silicate clay minerals. Geoderma 2013, 192, 249-253. [CrossRef]

9. He, H.P.; Guo, J.G.; Zhu, J.X.; Yang, D. An experimental study of adsorption capacity of montmorillonite, kaolinite and illite for heavy metals. Acta Mineral. Petrol. 2001, 20, 573-578.

10. Gong, T.; Zhu, Y. Spatial pattern of caliche nodule in surface soil of the hillslopes in Liudaogou catchment in the wind-water erosion crisscross zone of the Loess Plateau. Sci. Soil Water Conserv. 2016, 14, 42-49.

11. Teng, Z.H.; Liu, R.M. Research on calcareous nodules in the loess strata of China. Chin. Sci. Bull. 1990, 192, 1008-1011.

12. Wang, S.Y. Study on the Petrological Characteristics of $\mathrm{N}_{2}$ Red Clay in Northern Shanxi. Master's Thesis, China University of Mining and Technology, Xuzhou, China, 2017.

13. Gong, T.X. Study on the Distribution of Calcareous Nodules and Their Water Characteristics on Slopes in Loess Area. Master's Thesis, University of Chinese Academy of Sciences, Beijing, China, 2017.

14. Li, C.A.; Wu, J.P.; Cao, J.X. The morphology of loess calcareous nodules in northwest Hebei and their genesis dynamic characteristics and stratigraphic environmental significance. Earth Sci. 1995, 38, 511-514.

15. Yang, L.G.; Qiao, D.Y.; Hu, P.Y. Determination of thirteen elements in soil by inductively coupled plasma mass spectrometry with automatic digestion instrument. Soil Fertil. Sci. China 2019, 38, 89-93.

16. Wu, H.Z.; Meng, L.F. Liquid chromatography-UV determination of heavy metal ions in environmental samples using dispersive liquid-liquid microextraction coupled with magnetic nanoparticles. Appl. Ecol. Environ. Res. 2019, 17, 1571-1584. [CrossRef]

17. Lee, J.Y.; Chen, C.H.; Cheng, S.; Li, H.Y. Adsorption of $\mathrm{Pb}(\mathrm{II})$ and $\mathrm{Cu}(\mathrm{II})$ metal ions on functionalized large-pore mesoporous silica. Int. J. Environ. Sci. Technol. 2016, 13, 65-76. [CrossRef]

18. Melnyk, I.V.; Gdula, K.; Dbrowski, A.; Zub, Y.L. Magneto-sensitive adsorbents modified by functional nitrogen-containing groups. Nanoscale Res. Lett. 2016, 11, 61. [CrossRef] [PubMed]

19. Gao, B.Y.; Qiu, T.; Li, R.H.; Qin, R.; Zhang, G.; Li, X.; Zhang, Z. Investigation of heavy metal ions adsorption ability by thiol-modified corn stalk powder. J. Northwest A F Univ. -Nat. Sci. Ed. 2012, 40, 185-190.

20. Qin, H.F.; Zhang, W.M. Adsorption of lead and cadmium by hydroxyapatite coated quartz sands. Sci. Technol. Eng. 2018, 20, 183-189.

21. Kang, J.; Kim, T.; Park, J.; Lee, K.Y.; Park, D.H.; Park, S.; Kim, S.; Jung, Y. A mesoporous chelating polymer-carbon composite for the hyper-efficient separation of heavy metal ions. J. Nanosci. Nanotechnol. 2020, 20, 3042-3046. [CrossRef]

22. Tsao, T.M.; Chen, Y.M.; Sheu, H.S.; Zhuang, S.Y.; Shao, P.H.; Chen, H.W.; Shea, K.S.; Wang, M.K.; Shau, Y.H.; Chiang, K.Y. Red soil chemistry and mineralogy reflect uniform weathering environments in fluvial sediments, Taiwan. J. Soils Sediments 2012, 12, 1054-1065. [CrossRef]

23. Zhu, X.; Chen, H.; Li, W.; He, Y.; Brookes, P.C.; Xu, J. Aggregation kinetics of natural soil nanoparticles in different electrolytes. Eur. J. Soil Sci. 2014, 65, 206-217. [CrossRef]

24. Zhang, Z.Y.; Huang, L.; Liu, F.; Kuang Wang, M.; Ling Fu, Q.; Zhu, J. The properties of clay minerals in soil particles from two Ultisols, China. Clays Clay Miner. 2017, 65, 273-285. [CrossRef]

25. Chou, Y.M.; Song, S.R.; Tsao, M.T.; Lin, C.S.; Wang, M.K.; Lee, J.J.; Chen, F.J. Identification and tectonic implications of nano-particle quartz $(<50 \mathrm{~nm})$ by synchrotron $X$-ray diffraction in the Chelungpu fault gouge, Taiwan. Tectonophysics 2014, 619, 36-43. [CrossRef]

26. Ye, T.; Huang, L.; Zhang, K.Q.; Zhang, B.; Chang, H.; Liu, Z.J.; Du, L.Z. Evaluation of the combined removal of heavy metals by saponin and citric acid from municipal sewage sludges and metal stability features. Huanjing Kexue 2017, 38, 4850-4859. [CrossRef]

27. Wang, W.; Han, N.; Yang, C.; Zhang, W.; Miao, J.; Li, W.; Zhang, X. Fabrication of P(AN-MA)/rGO-g-PAO superhydrophilic nanofiber membrane for removal of heavy metal ions. J. Nanosci. Nanotechnol. 2020, 20, 1685-1696. [CrossRef]

28. Tofighy, M.A.; Mohammadi, T. Adsorption of divalent heavy metal ions from water using carbon nanotube sheets. J. Hazard. Mater. 2011, 185, 140-147. [CrossRef] [PubMed]

29. Peng, W.; Li, H.; Liu, Y.; Song, S. A review on heavy metal ions adsorption from water by graphene oxide and its composites. J. Mol. Liq. 2017, 230, 496-504. [CrossRef]

30. Gu, D.G.; Fein, J.B. Adsorption of metals onto graphene oxide: Surface complexation modeling and linear free energy relationships. Colloids Surf. A Physicochem. Eng. Asp. 2015, 481, 319-327. [CrossRef] 
31. Rahnama, E.; Bazrafshan, O.; Asadollahfardi, G. Application of data-driven methods to predict the sodium adsorption rate (SAR) in different climates in Iran. Arab. J. Geosci. 2020, 13, 1160. [CrossRef]

32. Zhu, L.; Wang, J.; Liu, J.; Nasir, M.S.; Zhu, J.; Li, S.; Liang, J.; Yan, W. Smart formaldehyde detection enabled by metal organic framework-derived doped electrospun hollow nanofibers. Sens. Actuators B Chem. 2021, 326, 128819. [CrossRef]

33. Liu, J.W.; Wang, J.N.; Zhu, L.; Chen, X.; Ma, Q.; Wang, L.; Wang, X.; Yan, W. A high-safety and multifunctional MOFs modified aramid nanofiber separator for lithium-sulfur batteries. Chem. Eng. J. 2021, 411, 128540. [CrossRef] 